\title{
Optimization of the Containers Train Loading Operations at Abidjan Terminal
}

\author{
Bakary KONE ${ }^{1}$, Ibrahima DIEDHIOU ${ }^{1}$, Coumba DIALLO ${ }^{1}$, \\ Salimata GUEYE DIAGNE ${ }^{1} \&$ Gabriel Birame NDIAYE ${ }^{1}$ \\ ${ }^{1}$ University Cheikh Anta Diop of Dakar \\ Correspondence: Coumba DIALLO, University Cheikh Anta Diop of Dakar.
}

Received: March 8, 2018 Accepted: March 30, 2018 Online Published: May 9, 2018

doi:10.5539/jmr.v10n4p19

URL: https://doi.org/10.5539/jmr.v10n4p19

\begin{abstract}
In a growing and competitive maritime world, it is necessary to improve the operational quality of port terminals in order to satisfy customers. This observation was made at the container terminal in Abidjan. In this paper, the goal is to minimize the overall duration of the transfer operations of the containers on railcars to neighboring countries. Considering the resources of the container terminal in Abidjan, we propose a non-linear programming model of the problem, we solved it using the AMPL language (Mathematical Programming Language) and we have used the KNITRO 10:2 solver for the solution.
\end{abstract}

Keywords: Containers, container train, Reach-Steaker, AMPL-KNITRO, railcar

\section{Introduction}

In view of the technological evolution in the maritime world, the improvements of operational performances have become a major challengefor maritime terminals. Each terminal must continually readjust and improve the quality of its operations in order to not only meet international standards, but also satisfy its customers (Ndey Ndiye, 2015). This need is observed in most maritime terminals, particularly the container terminal of Abidjan. With an extensive container distribution platform in import, export and transshipment, this container terminal plays a remarkable role in the port activities of Ivory Coast. The arrivals of combined export containers, delivery trucks and container train generate a huge demand of service. Some vehicles, such as the container train, wait a long time on the fleet before being serviced. Due to the size of the stockyard, the transfer time from containers to wagons is long, which also increases the cost of operations. It is therefore this time of wagon loading operations that must be reduced in order to improve the operational qualities of the container terminal of Abidjan. After the introduction, sections two and three are devoted respectively for the presentation of the problem and its mathematical formulation.

\subsection{State of the Art}

In order to contribute to decision-making, some researchers have been studied the subject and made important proposals. (Mustapha OUDANI, 2016) was interested in the transfer of containers to the rail yard of the multimodal terminal. He studied the problem of rail shuttle transfer, which consists in optimizing the transfer of a set of containers between maritime terminals and multimodal terminals. He modeled the scheduling problem of mainline trains for placement on the rail yard tracks and used a combined optimization and simulation approach. For (Khouala CHEBIL, 2011) the problem of planning container loading operations was first formulated as a mixed linear program. The objective function minimizes the completion time of handling operations by the courtyard gantries. The mathematical model is based on several hypotheses, taking into account both interference phenomena and non-productive movements. A heuristic approach such as Adaptive Large Neighborhood Research is being developed to solve this problem. Other researchers such as (Chen. L, \& Langevin .A, 2011) the authors respectively deal with the interference problem implicitly and the planning problem of several courtyard gantries during container loading operations. The objective of their work was to improve the processing efficiency of containers destined for export by the courtyard gantries. By developing a hypothesis in the mathematical model these authors considered two types of interference: collision and crossover gantries. By developing a hypothesis in the mathematical model these authors considered two types of interference: collision and crossover gantries. Thus in their work (Bakary KONE \& al, 2017) have proposed a linear model in mixed integers numbers to plan RTG operations in order to minimize the overall waiting time of container delivery trucks in Abidjan. In using it the authors used the AMPL programming language (A Mathematical programming language) Coupled with CPLEX solver for digital resolution. The results of their work have confirmed a significant reduction in the overall wait times for trucks delivered in the area of the container terminal in Abidjan. As for ( $\mathrm{Li} \&$ al, 2009.), courtyard gantries operations essentially contribute in lifting and 
moving containers, either for export or import, from the courtyard to the trucks or vice versa. Using the algorithm called Rolling-Horizon, they addressed the planning problem of single or multiple courtyard gantries and reduced the waiting time caused by the gantries and increasing terminal throughput. Otherwise (Lei L. \& al, 2008) have shown the importance of courtyard gantries and truck movement planning in improving the efficiency of a container terminal. Contrary to traditional truck haulage planning based on queue operations, the authors examined truck haulage time and time operation of the courtyard gantries during the simultaneous loading and unloading of containers. This problem, aimed at minimizing truck travel time, was solved with the Tabou algorithm and another algorithm called Immune Algorithm. The authors (Steeken D. \& al, 2005) have treated the problem of interference in an implicit way. The work deals with the planning problem of several courtyard gantries during container loading operations. The objective of this work is to improve the processing efficiency of containers intended for export by courtyard gantries. We took into account potential interferences that can occur. According to Chen and Langevin a minimal distance of five bays must be respected in order to avoid a potential collision between two courtyard gantries. Moreover, the authors elsewhere (Guo X. \& al, 2008) have focused on the problem of management of courtyard gantries sequences in real time. Integration of data in real time in the courtyard gantries management system allows a better use of the seaport resources and hence to improve the overall productivity of this port. The definition of this problem is based on the fact that each vehicle transports a single container and has accurate information and in real time on the arrival of the vehicles and the storage location. On their side, the authors ( Zhang, H.L, Jiang, \& al, 2008 ) consider that with inefficient gantries planning, the trucks will wait in the courtyard for loading the containers and subsequently the dock gantries will be inactive while waiting for the trucks, which will slow down the operation of the sequence of port operations. With regard to the specific container terminal case of Abidjan, this question was not addressed in the literature.

\section{Presentation of the Problem}

The container terminal in Abidjan is built on an area of 30 hectares. His park storage is divided into two large areas according to the gantry cranes used. An area under RTG (zone equipped with pneumatic gantries) very close to the port area and a non-RTG area gathering a large part of the ordinary and specific containers. It contains the rails used as a stop for container trains. In order to reduce the costs of the transfers on the wagons, the delivery service stacks containers in the non RTG area of the terminal when they land. Before the locomotive arrives at the park, the list of containers to transfer is received by the delivery service which verifies and updates the addresses of these containers through the operating system of the terminal. When the train arrives, after the administrative formalities, the list of containers is given to the gantry crane and the park managers The Reach Steaker loads the truck that makes the transfer to the wagons. But

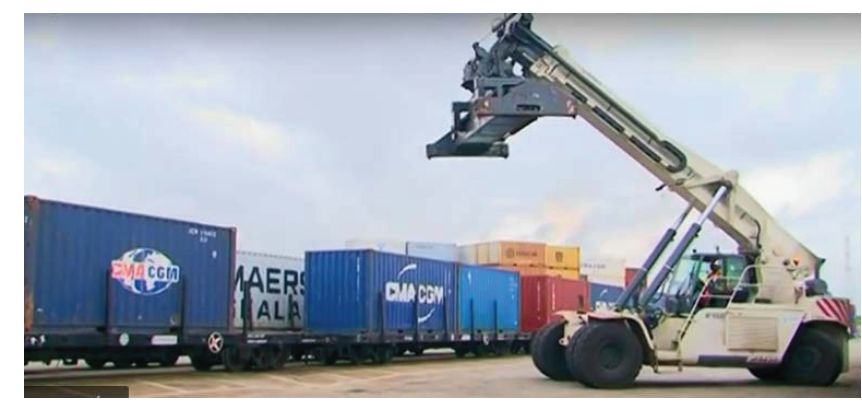

Figure 1. Loading operations of the container train

for the blocks close to the rail, the transfer is ensured by the gantry crane that moves the container from block to rail without using the truck (figure 1). Each container is transferred to the wagon which is appropriate to him. Considering the number of containers to be transferred and their positions dispersed in the park, the operations do not end in a reasonable time. Our contribution in this article is to propose a transfer scheduling on wagons in order to reduce the overall duration of operations.

\section{Mathematical Model}

The formulation of the mathematical model is done in several stages: In view of Abidjan Terminal's resources, we start with the setting of the hypotheses then we present the parameters, the decision variables, the objective function and finally the constraints.

\section{- Hypotheses}

They are acquired during our research at Abidjan Terminal and taken into account in the formulation of the problem.

a) The transfer of the containers from the park to the wagon is ensured by at most one truck. 
b) In the non RTG area, we have a single Reach Steaker that loads the truck and another Steaker is at the level of the rails ensuring loading on the wagon

\section{- Sets and indices of the model}

$C$ : Set of containers to be loaded indexed by $\mathrm{i}$ and $\mathrm{j}$.

$P$ : Set of containers stacked in the blocks where their transfers to the wagon do not require the use of a truck. They are transferred directly by the Steaker.

$W$ : Set of wagons of the train to be loaded indexed by w.

0 : Fictitious container index.

\section{- Parameters and indices of the model}

$h_{i}$ : Time totally needed to unload the container and load on the car $w$. It is performed by another steaker at the rails. $D_{i}$ : The start time for treatment of container i by Steaker.

$H_{i}$ : Loading time of the container i on the truck. It is performed by the Steaker on the park. It is defined by the sum of the evacuation time of the containers above and the time to load the container on the truck.

$t_{i j}$ : Steaker travel time between the positions of the containers i and the next Container $\mathrm{j}$ to load. $T_{i w}$ : Transfer time of the container i from its position on the park to the wagon which is affected. It is carried out either by the truck or by the Steaker according to the position on the park.

\subsection{The Variables}

$F_{i}$ The necessary (total) time of the unloading of the container $i$ on the wagon.

$X_{i w}= \begin{cases}1 & \text { if the container } i \text { is assigned to wagon } w \\ 0 & \text { otherwise }\end{cases}$

$U_{i}^{P}=\left\{\begin{array}{cc}1 & \text { if the container } i \text { is located in the zone } p \\ 0 & \text { otherwise }\end{array}\right.$

$Y_{i j}= \begin{cases}1 & \text { if the container } j \text { is loaded just after the container } i \\ 0 & \text { otherwise }\end{cases}$

\subsection{The Objective Function}

$$
\begin{gathered}
\operatorname{Min} \sum_{j \in C} \sum_{i \in C}\left(F_{i}-D_{i}\right) Y_{i j} \\
\text { Constraints } \\
D_{j} \geq\left(t_{i j}+D_{i}+H_{j}\right) Y_{i j} \quad \forall i, j \in C, i \neq j \\
F_{j} \geq\left(D_{j}+H_{j}+T_{j w}+h_{j}\right) x_{i w} \quad \forall j \in C, w \in W \\
U_{i}^{P}+U_{i}^{\bar{P}}=1 \quad \forall i \in C \\
D_{j}+H_{j}+t_{i j} \geq T_{w i}+h_{i}+T_{w j} \quad \forall i, j \in C, i \neq j . \\
D_{j} \leq\left(T_{w i}+h_{i}\right) Y_{i j} \quad \forall i, j \in C, i \neq j . \\
\sum_{j=1}^{|C|} Y_{i j}=1, \quad \forall i \in C, i \neq j . \\
\sum_{w \in W} x_{i w}=1, \quad \forall i \in C . \\
F_{j} \geq\left(F_{i}+H_{j}+t_{w j} x_{i w}+t_{j w^{\prime}} x_{j w^{\prime}}\right) Y_{i j} \quad \forall i, j \in C, i \neq j . \\
F_{i} \geq 0, \quad \forall i \in C \\
Y_{i j}, X_{i w}, U_{i}^{p} \in\{0,1\} \quad \forall i, j \in C
\end{gathered}
$$

In our work, the objective function 1 reduces the total time of container processing on wagons. Constraint 2 and 3 ensure that container $\mathrm{j}$ is loaded after the end of the treatment of the container (i). As for constraint 4 , it ensures that none of the containers cannot be located in both zones at the same time. Constraints 5 and 6 express that the truck follows the Reach Steaker in handling operations. At the level of constraint 7, it ensures that two trucks can't be treated simultaneously by the Reach Steaker. Constraint 8 ensures that a wagon can be assigned to one and one only container. As for constraint 9 , it deals with the order of transfer of the containers of the same zone. And finally the constraints 10 and 11 are the constraints of integrity. 


\section{Numerical Results}

Seen the size of our data, we used a traditional method to obtain concrete results. The importance of the choice of the itineraries of courtyard gantries and the allocation of containers to the wagons is such that the results of the simulations must be precise. Using the terminal data, we used the AMPL language and we used the KNITRO solver to test our model. After thirty minutes, the results of the simulation are shown in the table below. They propose the scheduling of the loading of the containers assigned to the wagons.

Table 1. Table of results

\begin{tabular}{ccc}
\hline Adress Cts & Dure transf (min) & wagon affect \\
\hline \hline HT V3 A. 4. 4 & 8 & 11 \\
HT V3 C. 3. 2 & 9 & 8 \\
HT V3 E. 1.4 & 13 & 7 \\
HT V3 B. 2.3 & 6 & 1 \\
HT V3 F. 1. 2 & 10 & 5 \\
HT HJ C. 3. 2 & 9 & 4 \\
HT A1 B. 2. 4 & 12 & 3 \\
HT A1 A. 4.1 & 11 & 2 \\
HT V2 C. 3.5 & 11 & 6 \\
HT V2 E. 1.4 & 8 & 12 \\
HT V1 D. 3.3 & 10 & 10 \\
HT V1 C. 4.5 & 14 & 9 \\
HT HA A. 3.2 & 13 & 15 \\
HT HA C. 4.2 & 9 & 14 \\
HT B1 D. 3.1 & 12 & 13 \\
\hline
\end{tabular}

In this Table, first column represent the positions of the containers in the park. In second place column, we have the duration of container handling. It concerns the times of loading it on the truck and his transfer on the wagon. Finally, the last column represents the numbers of the cars assigned.

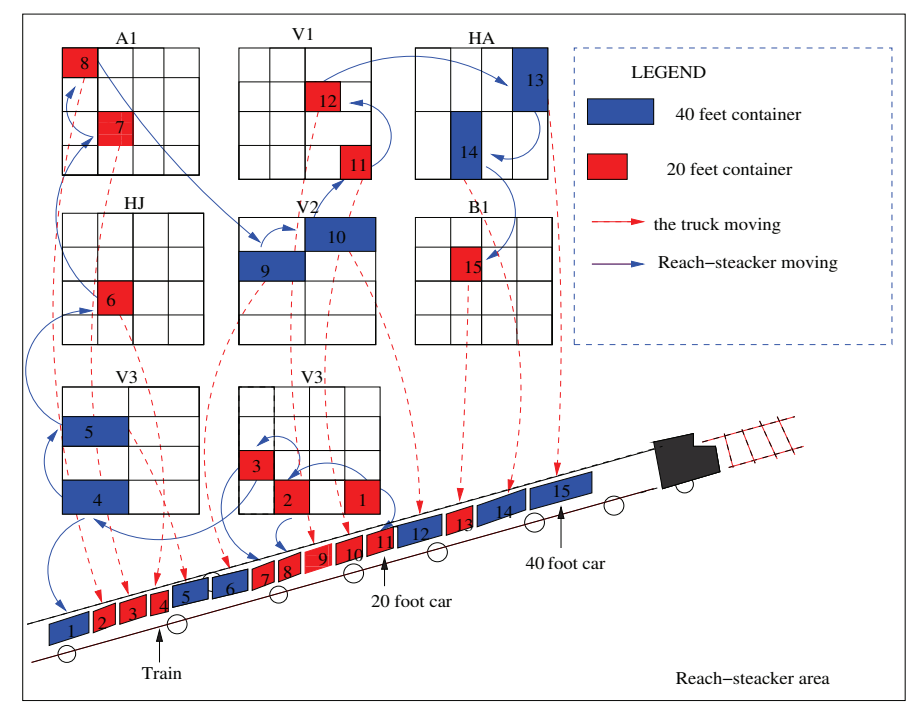

Figure 2. Process of loading container train

The figure 2 represent the different trajectories of the Reach-steaiker and the truck of container transfer. Comparing to the time taken by the gantry for these operations of transfer, we can say that the results of our simulation have been satisfactory because they allowed us to reduce the overall duration of the loading of the containers on the wagons. We went from 130 $\mathrm{mn}$ to $110 \mathrm{mn}$, a reduction of $20 \mathrm{mn}$ of loading time. This time saving allows the container terminal Abidjan to be more efficient in container handling 


\section{Conclusion}

In this article we have proposed a plan for the transfer of containers on wagons in the non-RTG area of the Abidjan container terminal. We have modeled the problem in the form of a non linear optimization program. By using data collected at the terminal, we performed a simulation with the AMPL language. In order to obtain precise results, we resorted to the KNITRO solver 10:2. After several minutes of compilation, the results obtained are satisfactory because they allowed us to save 20 minutes on the duration of the treatment.

In perspective the future work will take into account the specialized containers and we will use the Markov strings.

\section{Acknowledgements}

We thank the Director of the Container Terminal in Abidjan for welcoming us as an intern. We are very grateful to Mrs Asta Rosa CISSE for her moral support. We would like to express our gratitude to Mr. Laurent Bodji KASSI Director of Operations and all his team for their simplicity, loyalty and professional quality.

\section{References}

CHEBIL, K. (2011). Optimization of container movements in a maritime terminal. Master Ecole Polytechnique de Montreal , Departement de Mathematiques for Industrial Engineering, 15-45.

Chen. L., \& Langevin, A. (2011). Multiple yard cranes scheduling for loading operations in a container terminal. Engineering Optimization, 1-17. Christophe \& al. Introduction at CPLEX. ISIMA 2008/2009, P2 - 10

Ding, YI, Lin, G., \& Liang Cheng JI. (2012). Real Time RTG Dispatching Model and Algorithm for container Terminal with safe distance. Journal of convergence Information Technology(JCJT), 7(12).

Guo, X., Huang, S. Y., Hsu, W. J., \& Low, M. Y. H (2008). Yard crane dispatching based on real time data driven simulation for container terminals. Paper presented at the Proceedings of the 40th Conference on Winter Simulation. https://doi.org/10.1109/WSC.2008.4736380

KONE, B., GUEYE, S., \& et al. (2017). Optimization of the temporal performances of the RTG for Containers delivery in Abidjan Terminal International Journal of Applied Mathematics and Statistics., 56(1), 100-106.

Li, W., Wu, Y., Petering, M. E. H., Goh, M., \& Souza, R. D. (2009). Discrete time model and algorithms for container yard crane scheduling. European Journal of Operational Research, 198, 165-172. https://doi.org/10.1016/j.ejor.2008.08.019

Lei, L. Junqing, S., \& Mei, H. (2008). On Route Optimization of CTS in Container Terminal Based on Pool Strategy. Paper presented at the Control Conference, CCC 27th Chinese. https://doi.org/10.1109/CHICC.2008.4605510

Ndiye, N. (2015). Optimisation algorithm for solve the problem storage container for one container terminal. Laboratoire of Mathematical applied du Havre, 81-82.

OUDANI, M. (2016). Optimization of multimodal transport problems. Doctorat thesis of the normal university of Le Havre, 5-66.

Port Authority of Abidjan (PAA) (2015). Rapport d'activites, PAA, Abidjan

Steeken, D., Vob, S., \& Stahlbock, R. (2005). Container terminal operation and operations research-a classification and literature review. OR Spectrum, 26, 309-332.

Zhang, H. L., \& Jiang, Z. B. (2008). Simulation Studies of Heuristic approaches for dynamic scheduling of container terminal operations.International Journal of Modelling and Simulation, 28(4), 410-422. https://doi.org/10.1080/02286203.2008.11442494

\section{Copyrights}

Copyright for this article is retained by the author(s), with first publication rights granted to the journal.

This is an open-access article distributed under the terms and conditions of the Creative Commons Attribution license (http://creativecommons.org/licenses/by/4.0/). 